\title{
Life satisfaction as a health determinant among Polish adult population
}

\section{Monika Lopuszanska-Dawid ${ }^{1, *}$}

1 Józef Piłsudski University of Physical Education in Warsaw, Faculty of Physical Education, Department of Anthropology and Health Promotion, Marymoncka Street 34, 00-968 Warsaw 45, Poland

* Corresponding author: mlopdaw@gmail.com

With 2 figures and 2 tables

\begin{abstract}
Background: Mental factors may influence physical functioning and psychological well-being working positively on physical health. The aim of this study is to investigate the relationship between personal life satisfaction (LS) and biological condition in healthy males and females in Poland. Material and methods: The participants were 2102 men and 1397 women, 25-65 years of age, inhabitants of Wroclaw, Poland. LS was used as a measure of subjective well-being. Biological condition was evaluated by 13 objective medical measures characterizing a condition of the cardiovascular system, biochemistry, fitness and a level and distribution of general body adiposity. Results: Significant relationship has been found between LS and biological condition. Men having high LS are significantly more fit; have greater spine flexibility, better eye-hand coordination and more beneficial for health level of biochemical parameters comparing to their peers with lower LS. Men having low LS have more benefits health parameters concerning adiposity. Happier women have a significantly lower general body adiposity, better eye-hand coordination and spine flexibility, a lower level of total cholesterol and a more beneficial level of alkaline phosphatase. Conclusions: LS scale can detect a group dissatisfied men and women from the general population with a higher risk of having poorer health parameters. Significant is not only a relationship between LS and physical health, but also a long-term influence of LS on biological condition, which may be an effect of some specific models of health behavior and/or a worse professional and social situation.
\end{abstract}

Keywords: well-being; health; biological age; dissatisfaction; happiness; Poland

\section{Introduction}

Life satisfaction (LS) is an indicator of subjective well-being, and even when reported by healthy populations and measured by simple scales, it is strongly related with poor mental health (Horley 1984). LS is a persistent characteristic that is not related to mood changes over consecutive days and can be used as a barometer for determining how an individual adapts to their current life situation (Cantril 1965; KoivumaaHonkanen et al. 2001a; Koivumaa-Honkanen et al. 2001b). Prolonged life dissatisfaction and a poor social situation, personality problems, as well as a poor affective status might also constitute early signs of depression or predict future depression (Green et al. 1992; Koivumaa-Honkanen et al. 2000; Cole \& Dendukuri 2003; Koivumaa-Honkanen et al. 2004a; Swami et al. 2007). Studies have documented that LS in an important variable affecting disability due to both mental and somatic causes (Koivumaa-Honkanen et al. 2004b; Łopuszańska et al. 2013). Longitudinally, life dissatisfaction was associated with both unintentional and intentional injury death (Koivumaa-Honkanen et al. 2002), a higher risk of suicide throughout the 20-year follow-up period and has been considered a mortality predictor (Koivumaa-Honkanen et al. 2001b; Koivumaa-Honkanen et al. 2003; Bray \& Gunnell 2006; Swami et al. 2007). However, it is important that "happiness" predicts longevity among healthy populations, but may not cure illness in sick populations (Veenhoven 2008).

Such a strong relationship between LS and further life, its quality and length may result from a present state of individual's physical health. A great deal of research indicates strong correlation between LS and self-perceived health, even at controlling for demographic markers (Røysamb et al. 2003; Subramanian et al. 2005; Bishop et al. 2006). It has been proved that perceived health was the most important factor for life satisfaction in a mixed European sample (Melin et al. 2003; Delhey 2004) and self-rated health explained a significant amount of variance in concurrent ratings of self-esteem and life satisfaction (Benyamini et al. 2004). Some researchers suggest that the perception of overall health and the perception of life satisfaction show common characteristics. 
They have interpreted that health may influence people's responses to questions about life satisfaction even though such questions do not explicitly concern health (Borg et al. 2008). It should be borne in mind that this relationship may be two-directional. Happier people and those who were more satisfied with their lives at baseline have reported better health measured by self-rated health, absence of long-term, limiting health and physical conditions (Siahpush et al. 2008).

We may thus expect that the existing differences in the level of life satisfaction of the subjects and the mental discomfort of groups showing lower life satisfaction can have a significant relationship with the diversity of the widely perceived biological condition of men and women. Since decreased life satisfaction is considered to be a predictor of premature death, some primal symptoms of worse health conditions must appear in the first place, not only at the subjective level but, first of all, at the level of its objective measures.

The aim of our research is to assess the relationship between psychological well-being and the objective health condition in Polish adult men and women. The research hypothesis is that subjects who represent low life satisfaction have worse health condition and their aging processes are more advanced in comparison with their peers who are happy with their lives. We wish to obtain an answer to the question whether people having different levels of life satisfaction are different in their advancement of involution processes. We would also like to discover if adult men and women of high level of LS differ from their chronological age-mates of low LS in biological age, i.e. in the degree of advancement on the path leading towards the condition of old age.

\section{Material and methods}

The participants of this study were 3,499 persons $(2,102$ men and 1,397 women), aged 25-65 years, occupationally active, healthy inhabitants of the city of Wroclaw, Lower Silesia, Poland. The subjects were medically examined in the course of health screening surveys (mandatory routine preventive examinations required by the employer) in the Silesian Centre for Preventive Medicine 'DOLMED' in Wroclaw. The following inclusion criteria were applied: age 25-65 years, an employed person, and being free from overt Caucasian diseases. In order to eliminate the impact of human mobility on the biological condition (Szklarska et al. 2008), the important inclusion criteria was that participants of this study were residents of the city of Wroclaw for at least 5 years. The exclusion criteria encompassed: age under 25 or over 65 years, an unemployed or non-working person, being a chronically ill person or after surgical procedures during convalescence, being treated for mental disorders or taking drugs for mental illness, being a member of an ethnic minorities living in Poland, e.g. Romanians.

Personal life satisfaction (LS) has been used as a measure of subjective well-being of the examined men and women (Cantril 1965). LS has been evaluated on the basis of methodology proposed by Cantril (1965; Carpenter 1996). Self-evaluated life satisfaction measured by Cantril Ladder has a persistent nature and is not relative to the change of mood from one day to other (Koivumaa-Honkanen et al. 2000; Koivumaa-Honkanen et al. 2001b). LS is stable over time and is not sensitive to temporal fluctuations (Wylie 1989; Carpenter 1996; Koivumaa-Honkanen et al. 2005). The Cantril Ladder is a very easy tool and its brevity, ease of administration and respondents' approval are widely accepted by people which makes it very useful in population studies. One-question scales of life satisfaction are considered to be accurate because they are easy to use and answers are obtained very quickly. Moreover, what is most important, you can achieve high values of correlation rates, usually above 0.05 , between them and other more developed scales. A correlation rate of the Cantril Ladder with the main factor obtained in a factor analysis of 10 different scales of wellbeing has values of about 0.70 (Larsen et al. 1985), so it is only a little bit lower than the ones of more complex, much more time consuming multi-question scales.

Life satisfaction in this paper has been used (conceptualized) at domain-specific as the global level which allows people to weigh the importance of each life domain (work, health, leisure, wealth, etc.) according to their own personal system of values. This measure of life satisfaction is purely a more subjective criterion and multidimensional concept (Pelham \& Swann 1989; Diener et al. 1999). Since subjects are given the freedom to indicate any type of characteristic important to self-esteem, it can be used as a barometer for determining how an individual can adapt to their life, illness or bad events (Carpenter 1996). Low evaluation of life satisfaction can be an indicator that an individual is suffering from poor mental health and quality of life, and adjusting or adapting poorly to their illness experience (Carpenter 1996).

Cantril's methodology (Cantril 1965; Carpenter 1996), used to study physiological well-being, requires individuals to subjectively define high and low endpoints of a 10-point ladder prior to providing numerical ratings. Life satisfaction has been self-evaluated by the Cantril Ladder that illustrated as a scale with ten levels: "Imagine that the highest level represents the highest life satisfaction, while the lowest level represents the worst life satisfaction. Which level, in your opinion, is in agreement with your current life-time of the interview?" Because of social preference towards happy people and, in consequence, a higher risk of increasing one's self evaluation of life satisfaction in order to get better social approval, an anonymous survey instead of a face-to-face interview was conducted, which increased the reliability of the answers given by the respondents (Downie 1999). Life satisfaction scores were categorized as follows: very satisfied (LS: 8-10), medium satisfied (LS: 5-7) and dissatisfied (LS: 1-4).

Biological condition of the subjects has been evaluated by means of objective medical measures, excluding any subjective ones: 
1. Body Mass Index - index of weight-for-height $(\mathrm{BMI}=$ body weight $(\mathrm{kg}) /$ body height $\left.(\mathrm{m})^{2}\right)$;

2. subscapular skinfold measured in the straight position on the left of the body, a high and lower angle of the scapula by Lange caliper;

3. percent of body fat measured by Crook's method (Crook et al. 1966); this method is a combination of person's height and body weight and subscapular skin and fat fold.

4. systolic and diastolic blood pressure $(\mathrm{mmHg})$ measured in the sitting position by Avionics manometr, after at least 5 minute rest period;

5. biochemical and haematological blood parameters:
a. total cholesterol level (TCH) $\left(\mathrm{mg} \mathrm{dl}^{-1}\right)$;
b. glucose level $\left(\mathrm{mg} \mathrm{dl}^{-1}\right)$;
c. $\quad$ creatinine level $\left(\mathrm{mg} \mathrm{dl}^{-1}\right)$;
d. hemoglobin concentration $\left(\mathrm{g} \mathrm{dl}^{-1}\right)$;
e. count of erythrocytes $\left(\mathrm{mln} \mathrm{mm}^{-3}\right)$;
f. phosphatase level $\left(\mathrm{U} \mathrm{l}^{-1}\right)$;

6. eye-hand coordination; measurement of quickness of psychomotor reaction at an imposed pace, in the scope of perception and division of attention and vision and motor coordination measured by means of Piórkowsky's device; the indicator was the number of errors made at 93 impulses per minute;

7. spine flexibility measured by a depth of bends with straightened legs (a distance from stretched fingers to the ground in $\mathrm{cm})$.

Other data gathered on the subjects concerned their socioeconomic status including level of education, marital status, having children, as well as information on some elements of lifestyle, including cigarette smoking.

In order to evaluate the correlation between life satisfaction and biological condition of the subjects two extreme regarding life satisfaction groups of men and women have been distinguished. Biological condition of people declaring high (LS: 8-10) or low (LS: 1-4) life satisfaction were compared on the basis of the profile approach to biological age in adults proposed by Borkan \& Norris (1980). This method uses a number of simple regression equations as biological parameters considered, and the chronological age of individuals is treated as an independent variable. The profile approach to biological age allows the possibility that different body systems may age at different rates within the same individual.

The level of advancement of involution processes is a very good indicator of individuals' biological condition. Biological age regarding a specific trait is a deviation of the regression line of this characteristic towards the age. The idea of assessment of biological age assumes that for the characteristics showing a positive correlation with age, individuals whose values of the characteristic are above the average for their peers are biologically older,wheras those for whom the values of this characteristic are below the average are biologically younger. To convert the individual raw scores into biological age scores the following four stages of data transformation have been used (Borkan $\&$ Norris 1980):

1. Distinction of a simple linear regression for each of the 13 variables on age.

2. Calculation of residual values by taking away an expected value from an empirical value for each considered characteristic.

3. Showing residual values in the form of standard deviation (SD) by means of $\mathrm{Z}$ transformation (accounting for increased variance of data with age) in order to standardize them.

4. Conversion of data - because some of the characteristics show a negative correlation with age, standardized values of these characteristics were multiplied by -1 . Negative scores refer to lower biological age, and positive results to greater biological age.

As a result of this 4-stage procedure, 13 age-related variables have been transformed into 13 biological age scores reflecting men's and women's status relative to the one of their peers. A further advantage of the pattern profile approach was that males and females of different chronological ages could have the same biological scores, for example +1 SD for a given variable, indicating that their status relative to their chronological age peers was identical. Therefore, men and women of different chronological ages could be included in the same analysis without confounding the results. In summary, a subject who has a positive regression deviation in a specific biological parameter, they have biologically unfavourable parameter values, are biologically older and, therefore, they are more advanced in the aging processes in this parameter compared to their peers with a smaller value of SD. Biological age determined in this way reflects present biological condition and the level of advancement of involution changes.

Test $t$ was used to establish the significance of differences between the averages of each characteristic. Statistical analysis was performed using the STATISTICA 12.5 (StatSoft Inc. 2014) and $p$ values $\leq 0.05$ were considered as statistically significant.

\section{Results}

The percentages for socio-economic and lifestyle parameters for men and women are presented in Table 1. Most of the male subjects were educated at vocational level at most, were married and had one or two children. More than $61 \%$ of men participating in the study smoked cigarettes, generally about $11-20$ a day, while at least $71 \%$ had been smoking 
Table 1. The distribution of background characteristics (n, \%) for men and women from Poland ( $\mathrm{N}=3499)$.

\begin{tabular}{|c|c|c|}
\hline & $\begin{array}{l}\text { Men } \\
\text { n (\%) }\end{array}$ & $\begin{array}{c}\text { Women } \\
\text { n }(\%)\end{array}$ \\
\hline \multicolumn{3}{|l|}{ Level of education } \\
\hline $\begin{array}{l}\text { well-educated (college or } \\
\text { secondary school) }\end{array}$ & $468(22.3)$ & $749(53.6)$ \\
\hline $\begin{array}{l}\text { poorly educated (primary or } \\
\text { basic vocational school) }\end{array}$ & $1634(77.7)$ & $648(46.4)$ \\
\hline \multicolumn{3}{|l|}{ Marital status } \\
\hline never married & $155(7.4)$ & $170(12.2)$ \\
\hline married & $1841(87.5)$ & 1005 (71.9) \\
\hline divorced & $71(3.4)$ & $124(8.9)$ \\
\hline widowed & $35(1.7)$ & $98(7.0)$ \\
\hline \multicolumn{3}{|l|}{ Having children } \\
\hline no & $276(13.1)$ & $264(18.9)$ \\
\hline 1-2 children & $1345(64.0)$ & $938(67.1)$ \\
\hline 3-4 children & $438(20.8)$ & $181(12.9)$ \\
\hline 5 and more & $43(2.1)$ & $14(1.1)$ \\
\hline \multicolumn{3}{|l|}{ Cigarette smoking } \\
\hline no & $811(38.6)$ & $879(63.2)$ \\
\hline yes & $1278(61.4)$ & $512(36.8)$ \\
\hline \multicolumn{3}{|l|}{$\begin{array}{l}\text { Number of cigarettes } \\
\text { smoked per day }\end{array}$} \\
\hline $1-10$ cigarettes & $270(21.6)$ & $249(48.3)$ \\
\hline 11-20 cigarettes & $814(65.1)$ & $247(48.0)$ \\
\hline 21 cigarettes and more & $166(13.3)$ & $19(3.7)$ \\
\hline \multicolumn{3}{|l|}{ Years of smoking } \\
\hline $1-10$ years & $356(28.6)$ & $193(37.4)$ \\
\hline $11-20$ years & $540(43.3)$ & $228(44.2)$ \\
\hline 21 years and more & $351(28.1)$ & $95(18.4)$ \\
\hline
\end{tabular}

for at least 11 years. The women's group consisted of welleducated women, $54 \%$, most of them were married and had one or two children. Over $63 \%$ of the female subjects did not smoke cigarettes, and $52 \%$ of the women who smoked declared smoking more than 10 cigarettes a day, while almost $63 \%$ had been smoking for over 10 years.

Correlation coefficients for biological parameters with age in Polish men and women are presented in Table 2. Values of correlation rates of the analysed characteristics with age are in men from 0.06 to 0.36 , and in women from 0.10 to 0.52 and achieve high levels of statistical significance (Table 2).

In men there have been observed strong relationships between objective health parameters and subjective mental well-being (Fig. 1). In the scope of 12 out of 13 analysed biomedical characteristics there are statistically significant differences between average values of characteristics of people
Table 2. Correlation coefficients $\left(r_{p}\right)$ for all biological variables with age in Polish men and women.

\begin{tabular}{|l|c|c|}
\hline & Men & Women \\
\hline BMI & $0.22^{* * *}$ & $0.41^{* * *}$ \\
Infrascapular fold & $0.13^{* * *}$ & $0.31^{* * *}$ \\
Systolic pressure & $0.18^{* * *}$ & $0.38^{* * *}$ \\
Diasstolic pressure & $0.36^{* * *}$ & $0.52^{* * *}$ \\
Glucose & $0.27^{* * *}$ & $0.37 * * *$ \\
Total cholesterol & $0.21^{* * *}$ & $0.21^{* * *}$ \\
Erythrocyte & $0.16^{* * *}$ & $0.44^{* * *}$ \\
Hemoglobin & $-0.12^{* * *}$ & $0.11^{* * *}$ \\
Creatinine & $-0.13^{* * *}$ & $0.10^{* * *}$ \\
Phosphatase & 0.06 & $0.11^{* * *}$ \\
Eye-hand & $0.09^{* *}$ & $0.40^{* * *}$ \\
co-ordination & $0.36^{* * *}$ & $0.34^{* * *}$ \\
Flexibility of spine & $0.21^{* * *}$ & \\
\hline
\end{tabular}

$* * p \leq 0.01 ; * * * p \leq 0.001$

declaring high or low life satisfaction, while in 6 parameters these differences are at the level of ${ }^{* *} p \leq 0.01$. Men who are more satisfied with their lives compared to men having lower life satisfaction, have a significantly better biological condition in the physical capacity (greater spine flexibility and a better eye-hand coordination) and in some biochemical parameters - count of erythrocytes in the blood serum, level of hemoglobin, creatinine and alkaline phosphatase; so in these health parameters they have more beneficial biological values of these parameters and are biologically younger. In dissatisfied men the count of erythrocytes in the blood serum, level of hemoglobin, creatinine and alkaline phosphatase are slightly higher than in men with high LS, and they are significantly different from those of satisfied men. Elevated values of these parameters correspond to the older age and they may indicate a deterioration of health.

Men with lower life satisfaction are characterized by better health parameters concerning body fatness; they have a lower BMI, typical for younger people. They have a smaller average thickness of the subscapular skinfold, lower percentage of body fat content, and lower level of total cholesterol and glucose concentration in the blood serum, as well as lower values of diastolic blood pressure also. Therefore, in the characteristics concerning only body fatness, happier men have less beneficial biological values of these parameters (higher than average values of these characteristics), so they are biologically older in this biological features than men who are less satisfied with their lives.

Comprehensively, the occurring differences show that despite parameters concerning body fatness (e.g. BMI) happier men in the scope of the majority of the analysed biomedical features are less advanced in involution processes, have 


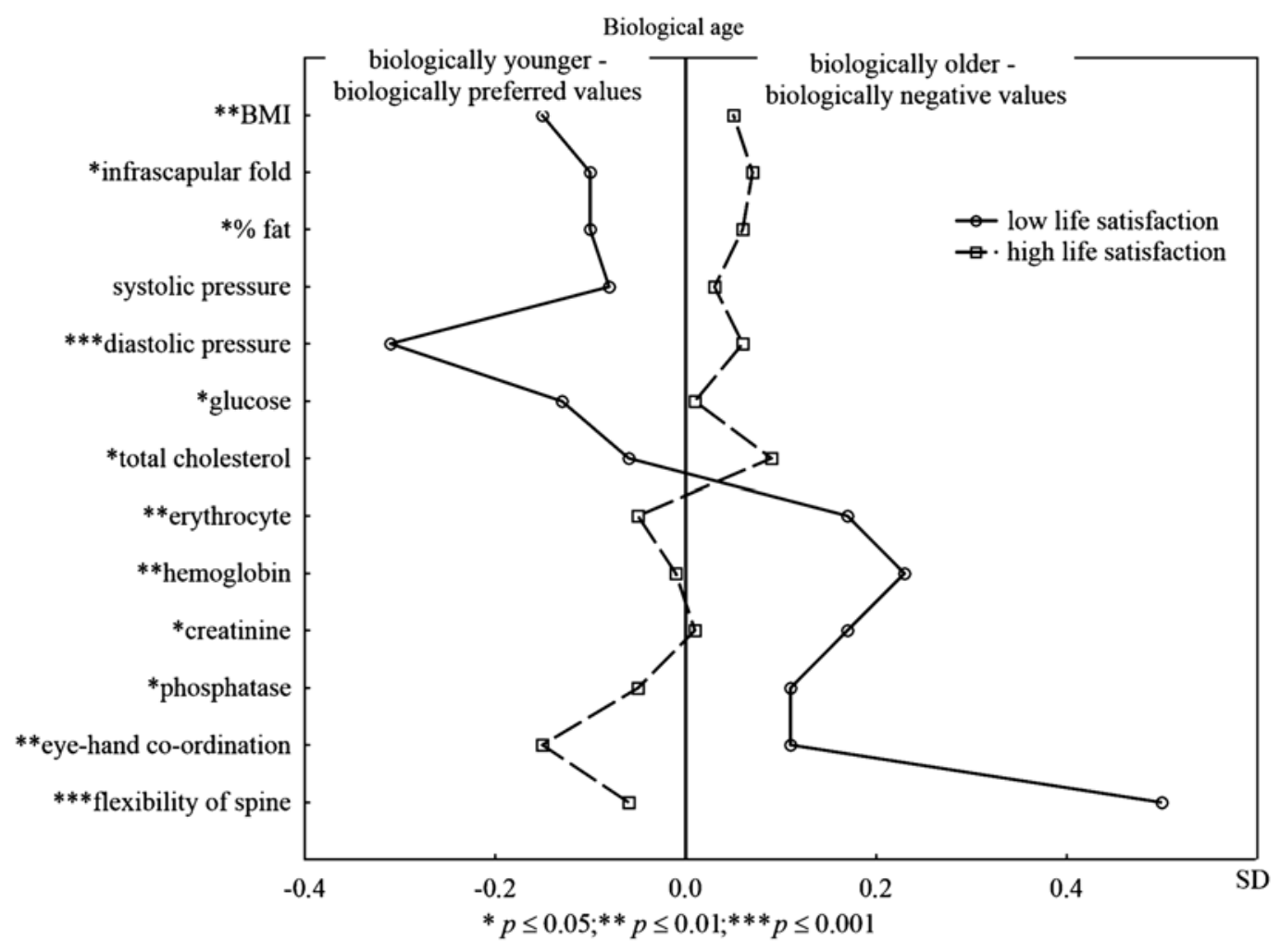

Fig. 1. The biological age profile comparison of men on their self-evaluated life satisfaction.

more beneficial biological values of characteristics, which makes them biologically younger compared to men who are less satisfied with their lives.

Figure 2 presents profiles of biological condition of women relative to their life satisfaction. Among women, in the scope of almost all of the analysed biomedical features, there have been observed differences between women with extreme levels of life satisfaction, while only 5 of the considered characteristics have been statistically significant, at the level of at least $* p \leq 0.05$. Happier women have a significantly lower level of BMI, better eye-hand coordination and spine flexibility, a lower level of total cholesterol and more favorable level of alkaline phosphatase in the blood serum. Moreover, despite the lack of statistical significance, a regular trend has been observed which indicates that women more satisfied with their lives in the scope of almost all of the characteristics achieve lower average standardized values of the analysed parameters, which means they have a better biological condition and are biologically younger compared to women with lower life satisfaction.

\section{Discussion}

It has been confirmed that relationships between subjective life satisfaction and objective health condition are much stronger in men than in women, which means that men's physical health is more strongly correlated with their mental state. In women, a high level of life satisfaction is generally correlated with better values of almost all health parameters and, therefore, with lower biological age. The relationships between life satisfaction and objective health condition are significant, and a diverse level of happiness in correlated with different biological age of male and female subjects. According to some authors, correlations of objective medical parameters with life satisfaction are weaker than correlations between self-evaluation of one's health condition with the feeling of happiness (Benyamini et al. 2004). This is explained by the fact that objective medical parameters do not include other, very important aspects of health. According to statistics, correlations of happiness and physical health vary between +.10 and +.40 and appear to be largely independent of age, gender, socio-economic status and personality. What is more, the correlations tend to be higher in patient populations than among general public (Veenhoven 2008). In the light of the above information, our results appear to be more reliable because we have shown strong correlations between objective health parameters and life satisfaction additionally in the population of healthy people, who can be regarded as representatives of general population. Thus, this short, clear LS scale can help to detect a group of dissatisfied men and women from 


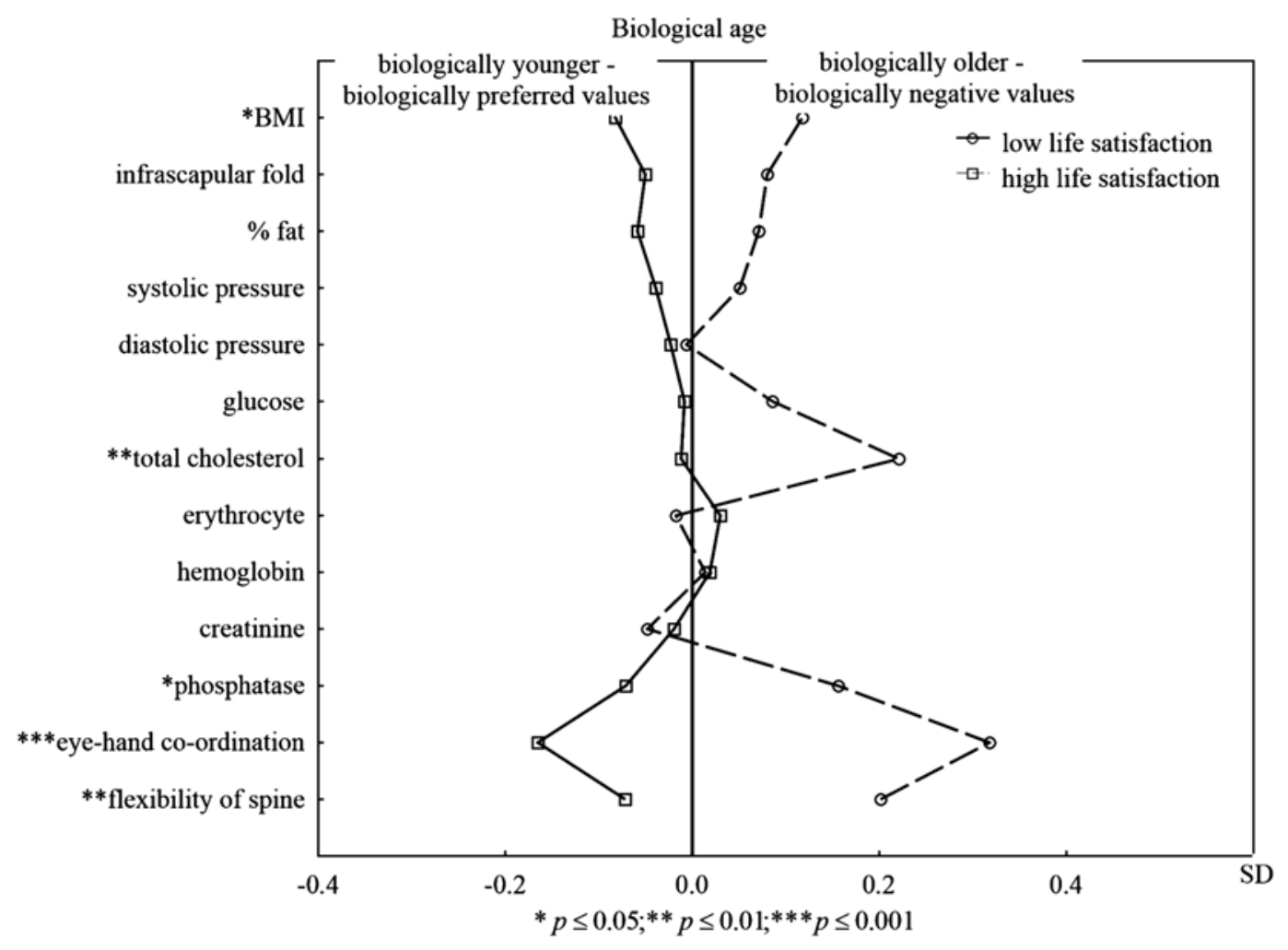

Fig. 2. The biological age profile comparison of women on their self-evaluated life satisfaction.

the general population with a higher risk of having poorer health parameters.

The results indicate a strong correlation between a mental factor - life satisfaction, and objective physical functioning, but do not provide any information on the direction of this relationship or its causes and effects. There arise questions whether psychological well-being works positively on physical health and whether it might protect against illness and if physical health itself influences the mental state.

It is commonly known that people having different mental states can show tendencies towards different types of health behavior. A specific lifestyle, e.g. smoking cigarettes, drinking alcohol, following a given diet, high recreational physical activity, healthy living and working environment, intensive social life, or motivation to self-care, have a significant relationship with the feeling of happiness, although directions of these relations are not always clear. Some authors indicate that low life satisfaction is connected with potential health hazards, such as poor health behavior or living alone (Cheng et al. 2008), so a negative perception of one's life can lead some people to intensify behavior making their health condition worse. In turn, accumulation of negative health behavior can lead to worsening one's health. The above regularity has been observed also in the Polish population (Lopuszańska et al. 2013). In adult men and women having low life sat- isfaction, the prevalence of health hazard behaviours, such as smoking cigarettes or frequently drinking alcohol, was significantly higher than in those with high LS. Moreover, there are premises indicating that happier people are more sensitive to signals of threat to their health (Sęk 1993) and take action to protect and improve their health more quickly. It could affect maintaining more favourable values of key health parameters, which results in better health, its more effective protection and slower process of aging in people satisfied with their lives. The above facts may explain the differences in health condition of people having high versus low life satisfaction.

Contrary to this, not all subjects satisfied with their lives show behavior aimed at protecting their health. The evidence of this is greater general body fatness and worse parameters of the cardiovascular system in men satisfied with their lives compared to their less happy peers. This result can be explained by a different model of health behavior of these men. A higher average BMI of men with high life satisfaction can be, for example, a consequence of the fact that they are more often non-smokers (Grant et al. 2009), but also of considerably decreased physical activity (Hayes \& Ross 1987). On the other hand, according to Rosmond \& Björntorp (2000), middle-aged, overweight men (BMI $\geq 25 \mathrm{~kg} / \mathrm{m}^{2}$ ) are characterized by a higher self-esteem, greater appetite and 
better family relations. Only after their satisfaction decreases and the level of cortisol becomes higher, redistribution of tissue in the abdominal area occurs. The importance of a relationship between a family situation and life satisfaction of men has been confirmed by the research conducted in the USA, which showed that as many as $46.8 \%$ of married men considered themselves happy, whereas among single men this percentage was only $21 \%$ (Lee et al. 1991). In our study among men satisfied with their lives, a bigger part comprised of married men and, as it has been proved, a diet followed by married people is more diverse, high-energy and more valuable. In addition, people living in relationships are used to eating breakfast and fruit and vegetables more often than single people and less often smoke cigarettes, which may also result in increased values of their BMI (Joung et al. 1995; Cavelaars et al. 2000). Lipowicz (2002; 2005) indicates similar regularities among Polish men and states that in the scope of key health parameters (e.g. a condition of the cardiovascular system, concentration of glucose in the blood serum, a state of the organ of vision) biological condition of single men is worse on average compared to married men. Men living alone, despite the fact that they are slimmer on average, have more advanced involution processes within key systems compared to their married peers.

A significant factor differentiating biological condition of people with different LS is their social status. People with different social status, in Poland still identified with an education status, are subjected to different external stimuli, e.g. different stressors, but they also differ as far as their awareness concerning importance of specific models of health behavior is concerned. Among people with lower life satisfaction, both among men and women, more frequent are those with a lower level of education $(85 \%$ and $76 \%$, respectively). It has been proved that education status determines lifestyle (smoking cigarettes, drinking alcohol, spending free time) and significantly affects biological condition of subjects (Kołodziej 1998; Łopuszańska et al. 2004). In turn, among men with higher LS prevail people with higher education, which is not a surprise when we take into consideration results showing that men's LS is mainly determined by their social status, education and salary (Lee et al. 1991; Łopuszańska 2005) and lowest-quartile of happiness is associated with poverty (Angner et al. 2009). An adverse consequence of this regularity, from the perspective of health, is the fact that men at the highest levels of the Cantril Ladder and having a high professional position are more likely to experience long-lasting stress of great magnitude, which results in a considerably higher risk level of heart and vascular diseases over the period of 10 years, compared to their peers less satisfied with their lives (Łopuszańska et al. 2013).

In case of female subjects, the obtained results are more clear than in males. Women with a higher level of LS, in almost all of the analysed characteristics, have more advantageous health parameters compared to their less happy peers.
The above facts have also been confirmed by the research of Brown et al. $(1998 ; 2000)$ who found, while they were studying the relationship between general adiposity and mental comfort of women between the age of 45-49 years, that an optimum range of BMI which correlates with high subjective satisfaction is $20-25 \mathrm{~kg} / \mathrm{m}^{2}$. Also, Finkelstein (2000) in his studies on almost 600 people obtained the highest values of life satisfaction at BMI between 20 and 25. Ball et al. (2004) have also confirmed the correlation between LS and BMI values with their results which show that women's weight was associated with life satisfaction and aspirations. In their view, young obese women were less likely to aspire to further education.

Contrary to men, women's life satisfaction is dependent on their social status the most, therefore marital status, family life, social contacts and others and much less related to their professional status (Lopuszańska 2005). Moreover, women may be less likely to develop Framingham Type A behavior than men (Haynes et al. 1978). In these studies most women with high LS live in relationships and have higher education. Higher level of education is known to be connected with a healthier lifestyle and with a smaller risk of engaging in anti-health behavior (Blaxter 1990). Highly educated subjects have better health parameters, are slimmer, have lower values of diastolic blood pressure, shorter reaction time, etc. (Wolański 1986). Additionally, a diet followed by people with poorer education is not as rich in fruit, vegetables, fish, is characterized by a lower content of proteins, high content of saturated fats and a very low content of vitamin A (Lasheras et al. 2001).

Considering the issue in question from the point of view of psychologists and in accordance with their general opinion, the strongest predictor of high life satisfaction are positive feelings of subjects themselves, which regulate their attitude to other objective factors playing a significant role in having good life satisfaction (Emmons 1991; Skevington 1999; Salovey et al. 2000; Sęk 2000; Keyes et al. 2002). Thus, situations determine human behavior and personality traits strongly control and modify them (Mischel 1968; Diener 1996). According to Emmons (1986), the condition necessary for maintaining high life satisfaction of subjects is a high level of happiness in the past and faith in a promising future. As we all know, reaction to positive events lasts longer and is more intensive compared to reaction to negative ones, so it is more connected with the increased level of satisfaction (Seidlitz et al. 1997). In western Europe and the USA there are programs being designed which are aimed at improving the quality of life by developing a positive attitude towards the outside world and increasing perception of positive stimuli (Herrman et al. 1996).

On the other hand, some authors claim that as much as $80 \%$ of variances of life satisfaction are heredity, and "an attempt to be happier is like trying to be taller" (Lykken \& Tellegen 1996; Røysamb et al. 2003). Despite strong genetic and personality determinants of the feeling of happiness 
(Neto 2001), some researchers suggest it can change substantially over time (Tay \& Kuykendall 2013).

\section{Conclusions}

Regardless of different psychologists' opinions, it should not be questioned that there is not only a strong correlation between LS and physical health, but also that life satisfaction has a long-term influence on biological condition (Koivumaa-Honkanen et al. 2002; Łopuszańska et al. 2013). From the perspective of public health, information about life satisfaction may be a useful mental and physical health indicator. Therefore, it should be added to the traditional collection of information about an individual patient (Higginson \& Carr 2001) and, along with the standard of living and the level of needs satisfaction, it should be considered as an important indicator of the condition of a given society. Relationships found between LS and health condition indicate a direction of activity for the social organizations whose aim is to improve social health. Maybe we could make whole societies healthier by increasing the level of their life satisfaction.

\section{Funding}

This study wasn't funded by any grant. The research was carried out in accordance with the statutory activity of scientific units.

\section{Competing interests}

Author declares that he has no conflict of interest.

\section{Ethical approval}

All procedures performed in studies involving human participants were in accordance with the ethical standards of the institutional and/or national research committee and with the 1964 Helsinki declaration and its later amendments or comparable ethical standards.

\section{References}

Angner, E., Ray, M.N., Saag, K.G. \& Allison, J.J. (2009): Health and Happiness among Older Adults. A Community-based Study. - J. Health Psychol. 14: 503-512.

Ball, K., Crawford, D. \& Kenardy, J. (2004): Longitudinal relationships among overweight, life satisfaction, and aspirations in young women. - Obes. Res. 12: 1019-1030.

Benyamini, Y., Leventhal, H. \& Leventhal, E. A. (2004): Self-rated oral health as an independent predictor of self-rated general health, self-esteem and life satisfaction. - Soc. Sci. Med. 59: 1109-1016.

Bishop, A.J., Martin, P. \& Poon, L. (2006): Happiness and congruence in older adulthood: a structural model of life satisfaction. Aging Ment. Health. 10: 445-453.

Blaxter, M. (1990): Health and lifestyle. - Routledge, London and New York.

Borg, C., Fagerström, C., Balducci, C., Burholt, V., Ferring, D., Weber, G., Wenger, C., Holst, G. \& Hallberg, I.R. (2008): Life satisfaction in 6 European countries: the relationship to health, self-esteem, and social and financial resources among people (aged 65-89) with reduced functional capacity. - Geriatr. Nur. 29: 48-57.

Borkan, G.A. \& Norris, A.H. (1980): Assessment of biological age using a profile of physical parameters. - J. Gerontol. 35: 177-184.

Bray, I. \& Gunnell, D. (2006): Suicide rates, life satisfaction and happiness as markers for population mental health. - Soc. Psychiatry Psychiatr. Epidemiol. 41: 333-337.

Brown, W.J., Dobson, A.J. \& Mishra, G. (1998): What is a healthy weight for middle aged women? - Int. J. Obes. Relat. Metab. Disord. 22: 520-528.

Brown, W.J., Mishra, G., Kenardy, J. \& Dobson, A. (2000): Relationships between body mass index and well-being in young Australian women. - Int. J. Obes. Relat. Metab. Disord. 24: 1360-1368.

Cantril, H. (1965): The pattern of human concerns. $1^{\text {st }}$ ed. - Rutgers University Press, New Brunswick (NJ).

Carpenter, J.S. (1996): Applying the Cantril methodology to study self-esteem: psychometrics of the self-anchoring self-esteem scale. - J. Nurs. Meas. 4: 171-189.

Cavelaars, A.E., Kunst, A.E., Geurts, J.J., Crialesi, R., Grötvedt, L., Helmert, U., Lahelma, E., Lundberg, O., Matheson, J., Mielck, A., Rasmussen, N.K., Regidor, E., do Rosário-Giraldes, M., Spuhler, T. \& Mackenbach, J.P. (2000): Educational differences in smoking: international comparison. - BMJ 320: 1102-1107.

Cheng, S.T., Fung, H.H. \& Chan, A.C. (2008): Living status and psychological well-being: social comparison as a moderator in later life. - Aging Ment. Health 12: 654-661.

Cole, M.G. \& Dendukuri, N. (2003): Risk factors for depression among elderly community subjects: a systematic review and meta-analysis. -Am. J. Psychiatry. 160: 1147-1156.

Crook, C.H., Bennett, C.A., Noorwood, W.D. \& Mahaffey, J.A. (1966): Evaluation of skinfold measurements and weight chart to measure body fat. - JAMA 198: 157-162.

Delhey, J. (2004): Life satisfaction in an enlarged Europe. Publication of The European Communities. - Luxembourg Office for Official, Luxembourg.

Diener, E. (1996): Traits can be powerful, but are not enough: lessons from subjective well-being. - J. Res. Pers. 30: 389-399.

Diener, E., Lukas, R.E. \& Oishi, S. (1999): Subjective well-being. In: Kahneman, D., Diener, E. \& Schwarz, N. (eds): Well-being: The foundations of hedonic psychology. - Russell Sage Foundation, New York, pp. 63-73.

Downie, R.S. (1999): The value and quality of life. - J.R. Coll. Physicians. Lond. 33: 378-381.

Emmons, R.A. (1986): Personal strivings: an approach to personality and subjective well-being. - J. Pers. Soc. Psychol. 51: 1058-1068.

Emmons, R.A. (1991): Personal strivings, daily life events, and psychological and physical well-being. - J. Pers. 59: 453-472.

Finkelstein, M.M. (2000): Body mass index and quality of life in a survey of primary care patients. - J. Fam. Pract. 49: 734-737.

Grant, N., Wardle, J. \& Steptoe, A. (2009): The relationship between life satisfaction and health behavior: a cross-cultural analysis of young adults. - Int. J. Behav. Med. 16: 259-268.

Green, B.H., Copeland, J.R., Dewey, M.E., Sharma, V., Saunders, P.A., Davidson, I.A., Sullivan, C. \& McWilliam, C. (1992): Risk factors for depression in elderly people: a prospective study. Acta Psychiatr. Scand. 86: 213-217. 
Hayes, D. \& Ross, C.E. (1987): Concern with appearance, health beliefs, and eating habits. - J. Health Soc. Behav. 28: 120-130.

Haynes, S.G., Feinleib, M., Levine, S., Scotch, N. \& Kannel, W.B. (1978): The relationship of psychosocial factors to coronary heart disease in the Framingham study. II. Prevalence of coronary heart disease. - Am. J. Epidemiol. 107: 384-402.

Herrman, H., Murphy, B., Freidin, S. \& Allen, N. (1996): Development of the WHO Quality of Life assessment instrument (WHOQOL) and its application in assessing the recovery from depression. - Eur. Neuropsychopharmacol. 6 (Suppl. 13): 166.

Higginson, I.J. \& Carr, A.J. (2001): Using quality of life measures in the clinical setting. - BMJ 322: 1297-1300.

Horley, J. (1984): Life satisfaction, happiness, and morale: two problems with the use of subjective well-being indicators. Gerontologist 24: 124-127.

Joung, M.A., Stronks, K., van de Mheen, H. \& Mackenbach, J.P. (1995): Health behaviors explain part of the differences in selfreported health associated with partner/marital status in The Netherlands. - J. Epidemiol. Commun. H. 49: 482-488.

Keyes, C.L., Shmotkin, D. \& Ryff, C.D. (2002): Optimizing wellbeing: the empirical encounter of two traditions. - J. Pers. Soc. Psychol. 82: 1007-1022.

Koivumaa-Honkanen, H., Honkanen, R., Viinamäki, H., Heikkilä, K., Kaprio, J. \& Koskenvuo, M. (2000): Self-reported life satisfaction and 20-year mortality in healthy Finnish adults. - Am. J. Epidemiol. 152: 983-991.

Koivumaa-Honkanen, H., Honkanen, R., Antikainen, R., Hintikka, J., Laukkanen, E., Honkalampi, K., et al. (2001a): Self-reported life satisfaction and recovery from depression in a 1-year prospective study. - Acta Psychiatr. Scand. 103: 38-44.

Koivumaa-Honkanen, H., Honkanen, R., Viinamäki, H., Heikkilä, K., Kaprio, J. \& Koskenvuo, M. (2001b): Life satisfaction and suicide: a 20-year follow-up study. - Am. J. Psychiatry. 158: 433-439.

Koivumaa-Honkanen, H., Honkanen, R., Koskenvuo, M., Viinamaki, H. \& Kaprio, J. (2002): Life dissatisfaction as a predictor of fatal injury in a 20-year follow-up. - Acta Psychiatr. Scand. 105: 444-450.

Koivumaa-Honkanen, H., Honkanen, R., Koskenvuo, M. \& Kaprio, J. (2003): Self-reported happiness in life and suicide in ensuing 20 years. - Soc. Psychiatry Psychiatr. Epidemiol. 38: 244-248.

Koivumaa-Honkanen, H., Kaprio, J., Honkanen, R., Viinamäki, H. \& Koskenvuo, M. (2004a): Life satisfaction and depression in a 15-year follow-up of healthy adults. - Soc. Psychiatry Psychiatr. Epidemiol. 39: 994-999.

Koivumaa-Honkanen, H., Koskenvuo, M., Honkanen, R.J., Viinamäki, H., Heikkilä, K. \& Kaprio, J. (2004b): Life dissatisfaction and subsequent work disability in an 11-year followup. - Psychol. Med. 34: 221-228.

Koivumaa-Honkanen, H., Kaprio, J., Honkanen, R.J., Viinamäki, H. \& Koskenvuo, M. (2005): The stability of life satisfaction in a 15-year follow-up of adult Finns healthy at baseline. - BMC Psychiatry. 18 (5): 4.

Kołodziej, H. (1998): The impact of social and ecological factors on biological fitness of adults. - Cent. Eur. J. Public Health. 2: 3-107.

Larsen, R.J., Diener, E. \& Emmons, R.A. (1985): An evaluation of subjective well-being measures. - Soc. Indic. Res. 17: 1-17.

Lasheras, C., Patterson, A.M., Casado, C. \& Fernandez, S. (2001): Effects of education on the quality of life, diet, and cardiovascu- lar risk factors in an elderly Spanish community population. Exp. Aging Res. 27: 257-270.

Lee, G.R., Seccombe, K. \& Shehan, A.L. (1991): Marital status and personal happiness: an analysis of trend data. - J. Marriage Fam. 53: 839-844.

Lipowicz, A., Gronkiewicz, S. \& Malina, R.M. (2002): Body mass index, overweight and obesity in married and never married men and women in Poland. - Am. J. Hum. Biol. 14: 468-475.

Lipowicz, A. \& Łopuszańska, M. (2005): Marital differences in blood pressure and the risk of hypertension among polish men. Eur. J. Epidemiol. 20: 421-427.

Lykken, D. \& Tellegen, A. (1996): Happiness is a stochastic phenomenon. - Psychol. Sci. 7: 186-189.

Łopuszańska, M. (2005): Life satisfaction and biological fitness of adult Polish men and women in 1985-2000 years. - Monographs of the Institute of Anthropology, Polish Academy of Sciences, nr 24, Wroclaw.

Łopuszańska, M., Szklarska, A. \& Jankowska, E.A. (2004): Health behaviors of adult men and women in Poland between 1984 and 1999. - Pol. J. Public. Health 114: 23-28.

Łopuszańska, M., Szklarska, A., Lipowicz, A., Jankowska, E.A. \& Kozieł, S. (2013): Life satisfaction and cardiovascular disease risk in Poland. - Arch. Med. Sci. 9: 629-634.

Melin, R., Fugl-Meyer, K.S. \& Fugl-Meyer, A.R. (2003): Life satisfaction in 18- to 64-year-old Swedes: in relation to education, employment situation, health and physical activity. - J. Rehabil. Med. 35: 84-90.

Mischel, W. (1968): Personality and assessment. - Wiley, New York.

Neto, F. (2001): Personality predictors of happiness. - Psychol. Rep. 88 (3 Pt 1): 817-824.

Pelham, B.W. \& Swann, W.B. Jr. (1989): From self-conceptions to self-worth: on the sources and structure of global self-esteem. J. Pers. Soc. Psychol. 57: 672-680.

Rosmond, R. \& Björntorp, P. (2000): Quality of life, overweight, and body fat distribution in middle-aged men. - Behav. Med. 26: 90-94.

Røysamb, E., Tambs, K., Reichborn-Kjennerud, T., Neale, M.C. \& Harris, J.R. (2003): Happiness and health: environmental and genetic contributions to the relationship between subjective well-being, perceived health, and somatic illness. - J. Pers. Soc. Psychol. 85: 1136-1146.

Salovey, P., Rothman, A.J., Detweiler, J.B. \& Steward, W.T. (2000): Emotional states and physical health. - Am. Psychol. 55: $110-121$.

Seidlitz, L., Wyer, Jr R.S. \& Diener, E. (1997): Cognitive correlates of subjective well-being: the processing of valenced life events by happy and unhappy persons. - J. Res. Pers. 31: 240-256.

Sęk, H. (1993): Jakość życia a zdrowie. - Ruch Prawniczy Ekonomiczny i Socjologiczny 2: 110-118.

Sęk, H. (2000): Społeczna psychologia kliniczna. - Wydawnictwo Naukowe PWN, Warszawa, p. 105.

Siahpush, M., Spittal, M. \& Singh, G.K. (2008): Happiness and life satisfaction prospectively predict self-rated health, physical health, and the presence of limiting, long-term health conditions. - Am. J. Health Promot. 23: 18-26.

Skevington, S.M. (1999): Measuring quality of life in Britain: introducing the WHOQOL-100. - J. Psychosom. Res. 47: 449-459.

StatSoft, Inc. (2014): STATISTICA (data analysis software system), version 12. - www.statsoft.com, Tulusa, USA. 
Subramanian, S.V., Kim, D. \& Kawachi, I. (2005): Covariation in the socioeconomic determinants of self-rated health and happiness: a multivariate multilevel analysis of individuals and communities in the USA. - J. Epidemiol. Commun. H. 59: 614. Swami, V., Chamorro-Premuzic, T., Sinniah, D., Maniam, T., Kannan, K., Stanistreet, D. \& Furnham, A. (2007): General health mediates the relationship between loneliness, life satisfaction and depression. A study with Malaysian medical students. - Soc. Psychiatry. Psychiatr. Epidemiol. 42: 161-166.

Szklarska, A., Lipowicz, A., Lopuszanska, M., Bielicki, T. \& Koziel, S. (2008): Biological condition of adult migrants and nonmigrants in Wrocław, Poland. - Am. J. Hum. Biol. 20: $139-145$

Tay, L. \& Kuykendall, L. (2013): Promoting happiness: the malleability of individual and societal subjective wellbeing. - Int. J. Psychol. 48: 159-176.
Veenhoven, R. (2008): Healthy happiness: Effect of happiness on physical health and the consequences for preventive health care. - J. Happiness. Stud. 9: 449-469.

Wolański, N. (1986): Education, income and some biological traits in women from South Poland populations. - Stud. Hum. Ecol. 7: $33-40$.

Wylie, R.C. (1989): Measures of self-concept. - University of Nebraska Press, Lincoln.

Manuscript received: 21 September 2017

Revisions required: 22 December 2017

Revised version received: 07 April 2018

Accepted: 10 April 2018 